\title{
Annual Report on the External Quality Assessment Scheme for Routine Hematology in Korea (2017)
}

Young Kyung Lee ${ }^{1,2}$ and Young Min $\mathrm{Kim}^{2}$

${ }^{1}$ Department of Laboratory Medicine, Hallym University College of Medicine, Chuncheon; ${ }^{2}$ Department of Laboratory Medicine, Hallym University Sacred Heart Hospital, Anyang, Korea
Under the Routine Hematology Program of the Korean Association of External Quality Assessment Service, complete blood count (CBC) and blood cell morphology proficiency tests were performed during 2017. We conducted two trials, sent three control materials for $\mathrm{CBC}$ testing, and posted two cell morphology pictures on the website for each trial. Of 1,646 laboratories, the mean response rates for $\mathrm{CBC}$ and blood cell morphology were $96.7 \%$ and $42.0 \%$, respectively. The distribution of equipment for $\mathrm{CBC}$ testing was similar to that of the previous year. The coefficient of variations for white blood cell counts, red blood cell counts, hemoglobin, hematocrit, and platelet counts were 3.7\%-4.7\%, 2.2\%-2.4\%, 1.5\%-3.0\%, 5.4\%$6.0 \%$, and $7.2 \%-10.2 \%$, respectively. More than $80 \%$ of the blood cell morphology tests were concordant among all of the trials, except for the HHI-17-03 trial. In 2017, the number of participating laboratories increased, and the performance was similar to that of the previous year.

(J Lab Med Qual Assur 2018;40:1-8)

Key Words: Laboratory proficiency testing, Blood cell count, Blood cell morphology
Corresponding author: Young Kyung Lee

Department of Laboratory Medicine, Hallym University Sacred Heart Hospital, Hallym University College of Medicine, 22 Gwanpyeong-ro 170beongil, Dongan-gu, Anyang 14068, Korea

Tel: +82-31-380-3930

Fax: +82-31-380-3934

E-mail: lyoungk@hallym.or.kr

pISSN: $2384-2458$

elSSN: 2288-7261

\section{서론}

대한임상검사정도관리협회(협회) 신빙도조사사업이 2016 년 차세대 신빙도조사사업으로 크게 개편된 이후 2017년은 차 세대 신빙도조사사업이 시행된 두 번째 해였다. 2017년 차세 대 신빙도조사사업의 일반혈액검사 프로그램은 2016년과 동 일하게 전혈구계산(complete blood count, $\mathrm{CBC)}$ 과 세포형태 (blood cell morphology), 2개 검사항목에 대해 연 2회 시행하 였다[1]. $\mathrm{CBC}$ 에는 백혈구 수(white blood cell count), 적혈구 수(red blood cell count), 혈색소(hemoglobin), 적혈구용적률 (hematocrit), 혈소판 수(platelet count)를 포함하도록 하였다.

\section{재료 및 방법}

일반혈액검사 프로그램에서는 $\mathrm{CBC}$ (백혈구 수, 적혈구 수, 혈색소, 적혈구용적률, 혈소판 수)와 세포형태, 2 개 검사항목 을 대상으로 각각 7월과 8월, 총 2회 실시하였으며, 각 회차당 3 개의 정도관리물질을 평가하도록 하였다.

$\mathrm{CBC}$ 를 위해서는 Hematology Control (Randox Laboratories Ltd., Crumlin, UK) 정도관리물질을 이용하였다. 각 회차마다 3 가지 농도의 정도관리물질로 구성하였다. 세포 형태검사를 위해서는 각 회차마다 2개의 세포사진을 간략한 임상소견과 함께 홈페이지에 게시하고 참가기관에서 판독결 


\section{Journal of LABORATORY MEDICINE and QUALITY ASSURANCE}

\section{Young Kyung Lee et al • Annual Report on EQA for Routine Hematology}

과에 해당하는 세포형태검사 판독코드를 입력하도록 하였다.

정도관리물질은 계약 택배를 이용하여 발송하였는데, 1 회차 는 7월 3일에, 2회차는 8월 29일에 발송하였다. 검사결과는 차 세대 신빙도조사사업 홈페이지에 입력하도록 하였고, 입력기 간 종료 후 입력결과에 대해 데이터 오류를 검증한 후 통계분 석을 시행하였다.

$\mathrm{CBC}$ 검사인 백혈구 수, 적혈구 수, 혈색소, 적혈구용적률, 혈소판 수 결과는 전체 기관, 제조회사별, 측정기기별 통계분 석을 시행하였다. 측정기기별 분석에서는 유사모델인 경우 한 군으로 묶어 통계분석을 시행하였다.

통계분석은 평균, 표준편차(standard deviation, $\mathrm{SD}$ ), 변 이계수(coefficient of variation, CV), 중간값, 최소값, 최대 값을 구하였으며, 각 기관에 대해 표준편차지수(standard deviation index, $\mathrm{SDI}$ 를 산정하였다[2]. 평균, $\mathrm{SD}, \mathrm{CV}$ 는 해 당 분류별 분석에서 75 percentile 값(Q3)과 25 percentile 값 (Q1)의 차(Q3-Q1; interquartile range, IQR)의 1.5배를 초 과하여 $\mathrm{Q} 1$ 보다 낮거나, $\mathrm{Q} 3$ 보다 높은 결과값 $(<\mathrm{Q} 1-1.5 \times \mathrm{IQR}$ 또는 $>\mathrm{Q} 3+1.5 \times \mathrm{IQR}$ )은 이상치(outlier)로 제거한 후 분석 하였다[3]. 각 분류에 해당하는 기관 수가 10 개 미만인 경우에 는 평균과 $\mathrm{SD}, \mathrm{CV}, \mathrm{SDI}$ 를 구하지 않았고, 기관 수가 3 개 미만 인 경우에는 중간값도 구하지 않았다.

세포형태검사에 대한 분석은 각 세포별로 답한 기관 수와 백

Table 1. Response rate of laboratories that participated in the proficiency tests that were performed under the Routine Hematology Program

\begin{tabular}{|c|c|c|c|c|c|c|c|}
\hline Test items & Trial & Participants & $\begin{array}{c}\text { Sample } \\
\text { delivery date }\end{array}$ & $\begin{array}{l}\text { Participating } \\
\text { laboratories }\end{array}$ & $\begin{array}{l}\text { Response } \\
\text { date }\end{array}$ & $\begin{array}{c}\text { Participants } \\
\text { who responded }\end{array}$ & $\begin{array}{c}\text { Response } \\
\text { rate (\%) }\end{array}$ \\
\hline \multirow[t]{3}{*}{ Complete blood count } & 1 st & 1,646 & 2017.7 .3 & 1,474 & 2017.7. 14 & 1,447 & 98.2 \\
\hline & 2nd & 1,646 & 2017.8.29 & 1,505 & 2017.9.8 & 1,435 & 95.3 \\
\hline & Mean & & & $1,489.5$ & & 1,441 & 96.7 \\
\hline \multirow[t]{3}{*}{ Blood cell morphology } & 1 st & 1,646 & 2017.7 .3 & 1,474 & 2017.7. 14 & 628 & 42.6 \\
\hline & 2nd & 1,646 & 2017.8. 29 & 1,505 & 2017.9. 8 & 621 & 41.3 \\
\hline & Mean & & & $1,489.5$ & & 624.5 & 42.0 \\
\hline
\end{tabular}

Table 2. Equipment used for complete blood count

\begin{tabular}{|c|c|c|c|c|}
\hline Manufacturer & 1 st & 2nd & Mean & $\%$ \\
\hline Sysmex & 619 & 618 & 618.5 & 42.9 \\
\hline Nihon Kohden Corp. & 146 & 142 & 144 & 10.0 \\
\hline Siemens Healthcare Diagnostics Inc. & 128 & 133 & 130.5 & 9.1 \\
\hline Shenzhen Mindray Bio-Medical Electronics Co. Ltd. & 132 & 127 & 129.5 & 9.0 \\
\hline Horiba Medical & 118 & 117 & 117.5 & 8.2 \\
\hline Beckman Coulter Inc. & 108 & 108 & 108 & 7.5 \\
\hline Abbott & 47 & 40 & 43.5 & 3.0 \\
\hline Boule & 32 & 32 & 32 & 2.2 \\
\hline Orphee SA & 28 & 28 & 28 & 1.9 \\
\hline Erba Diagnostics & 9 & 10 & 9.5 & 0.7 \\
\hline URIT Medical Electronic Co. Ltd. & 9 & 10 & 9.5 & 0.7 \\
\hline Samsung Electronics & 5 & 5 & 5 & 0.3 \\
\hline Shenzhen Genius Electonics Co. Ltd. & 3 & 3 & 3 & 0.2 \\
\hline Others & 62 & 62 & 62 & 4.3 \\
\hline Total & 1,447 & 1,435 & 1,441 & 100 \\
\hline
\end{tabular}

The instruments used were from the following companies: Sysmex (Kobe, Japan), Nihon Kohden Corp. (Tokyo, Japan), Siemens Healthcare Diagnostics Inc. (Tarrytown, NY, USA), Shenzhen Mindray Bio-Medical Electronics Co. Ltd. (Shenzhen, China), Horiba Medical (Montpellier, France), Beckman Coulter Inc. (Miami, FL, USA), Abbott (Abbott Park, IL, USA), Boule (Stockholm, Sweden), Orphee SA (Geneva, Switzerland), Erba Diagnostics (Mannheim, Germany), URIT Medical Electronic Co. Ltd. (Guangxi, China), Samsung Electronics (Suwon, Korea), and Shenzhen Genius Electonics Co. Ltd. (Shenzhen, China). 
Journal of LABORATORY MEDICINE and QUALITY ASSURANCE

Young Kyung Lee et al • Annual Report on EQA for Routine Hematology

Table 3. Proficiency test results for complete blood count

\begin{tabular}{|c|c|c|c|c|c|c|c|c|}
\hline Item & $\begin{array}{c}\text { No. of } \\
\text { participants }\end{array}$ & Median & Min & Max & Mean \pm SD & CV (\%) & $\begin{array}{l}\text { No. except } \\
\text { outliers }\end{array}$ & Outliers (\%) \\
\hline \multicolumn{9}{|l|}{1 st } \\
\hline \multicolumn{9}{|l|}{ WBC count } \\
\hline HH-17-01 & 1,446 & 16.32 & 0.44 & 19.40 & $16.305 \pm 0.631$ & 3.9 & 1,378 & 4.7 \\
\hline HH-17-02 & 1,446 & 5.70 & 0.15 & 59.80 & $5.703 \pm 0.211$ & 3.7 & 1,372 & 5.1 \\
\hline НH-17-03 & 1,446 & 9.10 & 0.26 & 92.80 & $9.083 \pm 0.379$ & 4.2 & 1,391 & 3.8 \\
\hline \multicolumn{9}{|l|}{ RBC count } \\
\hline HH-17-01 & 1,446 & 5.50 & 1.93 & 6.22 & $5.505 \pm 0.122$ & 2.2 & 1,393 & 3.7 \\
\hline HH-17-02 & 1,446 & 5.16 & 1.78 & 7.91 & $5.150 \pm 0.113$ & 2.2 & 1,404 & 2.9 \\
\hline HH-17-03 & 1,446 & 4.56 & 1.26 & 6.86 & $4.553 \pm 0.108$ & 2.4 & 1,370 & 5.3 \\
\hline \multicolumn{9}{|l|}{ Hemoglobin } \\
\hline HH-17-01 & 1,447 & 15.7 & 6.1 & 48.3 & $15.70 \pm 0.28$ & 1.8 & 1,399 & 3.3 \\
\hline HH-17-02 & 1,47 & 14.9 & 9.5 & 45.7 & $14.91 \pm 0.27$ & 1.8 & 1,417 & 2.1 \\
\hline HH-17-03 & 1,447 & 13.7 & 12.5 & 43.4 & $13.74 \pm 0.22$ & 1.6 & 1,368 & 5.5 \\
\hline \multicolumn{9}{|l|}{ Hematocrit } \\
\hline HH-17-01 & 1,446 & 44.5 & 15.4 & 57.8 & $44.19 \pm 2.60$ & 5.9 & 1,414 & 2.2 \\
\hline HН-17-02 & 1,446 & 42.7 & 13.5 & 65.1 & $42.42 \pm 2.32$ & 5.5 & 1,399 & 3.3 \\
\hline HH-17-03 & 1,446 & 39.3 & 7.9 & 58.7 & $38.91 \pm 2.34$ & 6.0 & 1,386 & 4.1 \\
\hline \multicolumn{9}{|l|}{ Platelet count } \\
\hline HH-17-01 & 1,446 & 381 & 72 & 4,240 & $381.0 \pm 30.8$ & 8.1 & 1,390 & 3.9 \\
\hline HH-17-02 & 1,446 & 77 & 41 & 8,000 & $76.8 \pm 7.9$ & 10.2 & 1,371 & 5.2 \\
\hline HH-17-03 & 1,446 & 234 & 10 & 2,640 & $233.4 \pm 17.0$ & 7.3 & 1,343 & 7.1 \\
\hline \multicolumn{9}{|l|}{ 2nd } \\
\hline \multicolumn{9}{|l|}{ WBC count } \\
\hline HH-17-04 & 1,433 & 7.80 & 0.22 & 88.00 & $7.804 \pm 0.320$ & 4.1 & 1,372 & 4.3 \\
\hline НH-17-05 & 1,433 & 2.50 & 2.02 & 24.00 & $2.515 \pm 0.119$ & 4.7 & 1,398 & 2.4 \\
\hline HH-17-06 & 1,433 & 9.00 & 0.29 & 88.00 & $8.976 \pm 0.355$ & 3.9 & 1,360 & 5.1 \\
\hline \multicolumn{9}{|l|}{$\mathrm{RBC}$ count } \\
\hline HH-17-04 & 1,433 & 2.05 & 0.07 & 5.62 & $2.047 \pm 0.046$ & 2.3 & 1,367 & 4.6 \\
\hline HH-17-05 & 1,433 & 2.08 & 0.47 & 5.28 & $2.080 \pm 0.046$ & 2.2 & 1,375 & 4.0 \\
\hline HH-17-06 & 1,433 & 4.71 & 1.55 & 5.61 & $4.704 \pm 0.104$ & 2.2 & 1,369 & 4.5 \\
\hline \multicolumn{9}{|l|}{ Hemoglobin } \\
\hline HH-17-04 & 1,435 & 6.5 & 5.4 & 15.8 & $6.47 \pm 0.19$ & 3.0 & 1,401 & 2.4 \\
\hline HH-17-05 & 1,435 & 6.1 & 5.1 & 15.0 & $6.07 \pm 0.16$ & 2.6 & 1,398 & 2.6 \\
\hline HH-17-06 & 1,435 & 13.8 & 1.4 & 15.2 & $13.84 \pm 0.21$ & 1.5 & 1,354 & 5.6 \\
\hline \multicolumn{9}{|l|}{ Hematocrit } \\
\hline HH-17-04 & 1,433 & 19.4 & 0.4 & 47.8 & $19.37 \pm 1.07$ & 5.5 & 1,372 & 4.3 \\
\hline НH-17-05 & 1,433 & 18.8 & 4.2 & 46.2 & $18.78 \pm 1.05$ & 5.6 & 1,358 & 5.2 \\
\hline HH-17-06 & 1,433 & 40.3 & 13.8 & 85.7 & $39.98 \pm 2.17$ & 5.4 & 1,353 & 5.6 \\
\hline \multicolumn{9}{|l|}{ Platelet count } \\
\hline HH-17-04 & 1,433 & 465 & 135 & 1,369 & $466.4 \pm 33.8$ & 7.3 & 1,398 & 2.4 \\
\hline HH-17-05 & 1,433 & 141 & 78 & 446 & $142.1 \pm 11.8$ & 8.3 & 1,404 & 2.0 \\
\hline НH-17-06 & 1,433 & 250 & 126 & 515 & $250.2 \pm 18.0$ & 7.2 & 1,375 & 4.0 \\
\hline
\end{tabular}

Abbreviations: WBC, white blood cell; RBC, red blood cell. 


\section{Journal of LABORATORY MEDICINE and QUALITY ASSURANCE}

\section{Young Kyung Lee et al • Annual Report on EQA for Routine Hematology}

분율을 구하였다. 각 기관별 분석결과는 홈페이지에서 직접 조 회 및 출력할 수 있도록 하였다.

\section{결과}

\section{1. 신빙도조사사업 참여기관}

2017년 일반혈액검사 프로그램은 총 1,646 기관이 신청하였 고, 1 회차에 1,474 기관, 2 회차에 1,505 기관에 검체를 배송하 였다. $\mathrm{CBC}$ (백혈구 수, 적혈구 수, 혈색소, 적혈구용적률, 혈소 판 수) 결과를 회신한 기관은 1 회차 1,447 기관, 2 회차 1,435 기 관으로 평균 결과 회신율은 $96.7 \%$ 였다. 세포형태검사 결과를 회신한 기관은 1 회차 628 기관, 2 회차 621 기관으로 평균 결과 회신율은 $42.0 \%$ 였다(Table 1).

\section{Complete blood count 측정기기 사용현황}

결과를 회신한 기관에서 $\mathrm{CBC}$ 측정에 이용한 자동분석기 기는 제조사별로 분류하였을 때 Sysmex (Kobe, Japan)가 $42.9 \%$ 로 가장 많았고, Nihon Kohden Corp. (Tokyo, Japan) 10.0\%, Siemens Healthcare Diagnostics Inc. (Tarrytown, NY, USA)가 9.1\%, Shenzhen Mindray Bio-Medical Electronics Co. Ltd. (Shenzhen, China)가 9.0\%, Horiba
Medical (Montpellier, France)가 8.2\%, Beckman Coulter Inc. (Miami, FL, USA)가 7.5\% 순이었다(Table 2).

\section{Complete blood count}

백혈구수는 평균값 $2,515 / \mu \mathrm{L}-16,305 / \mu \mathrm{L}$ 범위에서 전체기관 $\mathrm{CV}$ 가 3.7\%-4.7\%였고, 적혈구 수는 평균값 $2.047 \times 10^{6} / \mu \mathrm{L}-$ $5.505 \times 10^{6} / \mu \mathrm{L}$ 범위에서 전체기관 $\mathrm{CV}$ 가 $2.2 \%-2.4 \%$ 였다. 혈 색소는 평균값 $6.07 \mathrm{~g} / \mathrm{dL}-15.70 \mathrm{~g} / \mathrm{dL}$ 범위에서 전체기관 $\mathrm{CV}$ 가 1.5\%-3.0\%였고, 적혈구용적률은 평균값 $18.78 \%-44.19 \%$ 범위에서 전체기관 CV가 5.4\%-6.0\%였다. 혈소판 수는 평 균값 $76.8 \times 10^{3} / \mu \mathrm{L}-466.4 \times 10^{3} / \mu \mathrm{L}$ 범위에서 전체기관 $\mathrm{CV}$ 가 $7.2 \%-10.2 \%$ 였다(Table 3 ).

\section{4. 세포형태}

세포형태는 매 회차마다 2개의 사진을 게시하였다. 출제 의 도와 최다빈도로 일치하는 결과를 기준으로 평가하였을 때, 1 회차 HHI-17-01 (Fig. 1A)는 basophil에 95.4\%, HHI-17-02 (Fig. 1B)는 rouleaux formation에 $97.3 \%$ 의 일치율은 보였 다. 2회차 HHI-17-03 (Fig. 1C)은 blast에 68.1\%로 비교적 낮은 일치율을 보였으며, 이 외의 답으로 reactive lymphocyte (14.8\%), lymphocyte (7.2\%)로 답한 경우도 있었다. 2회

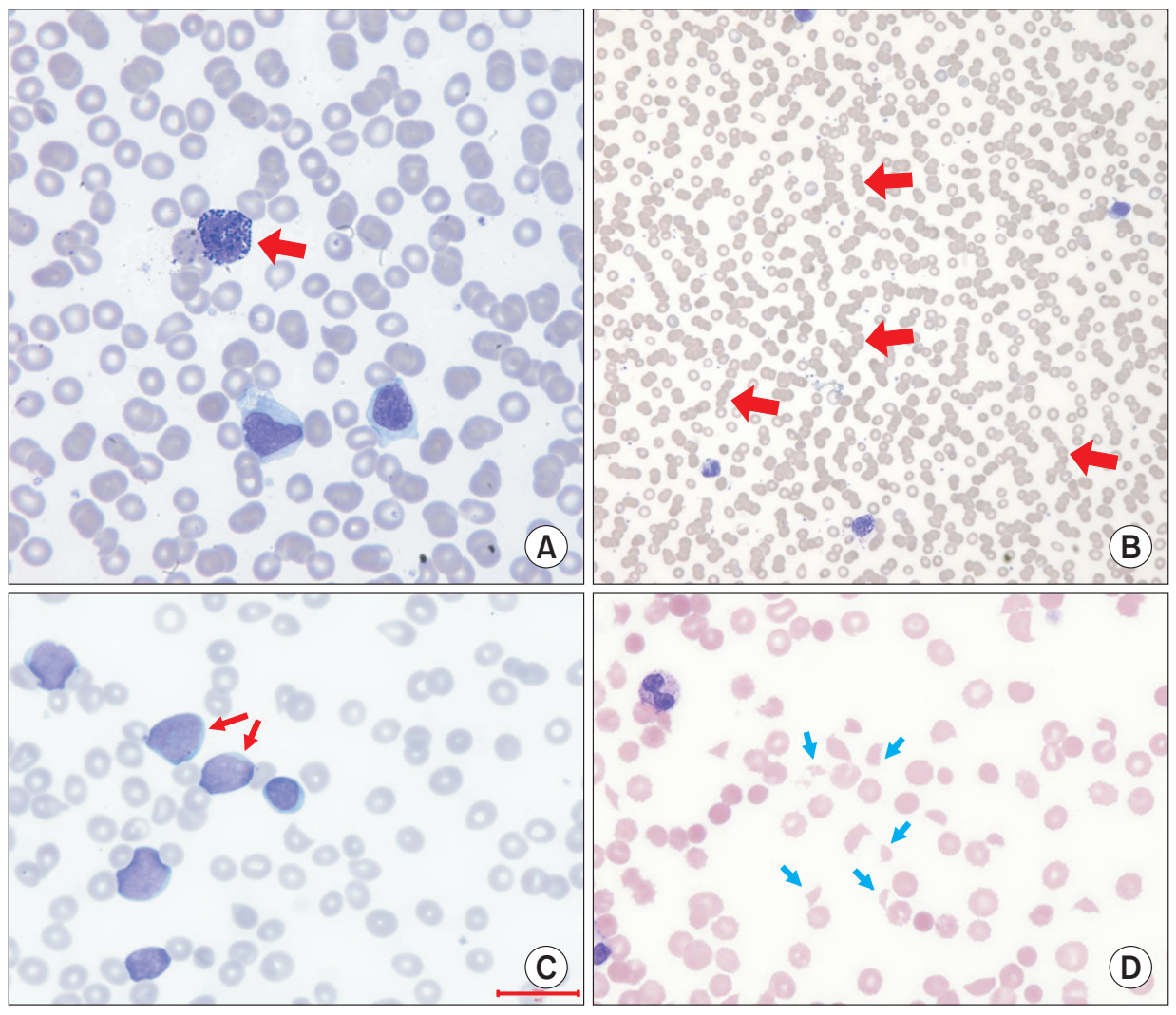

Fig. 1. Cell morphology pictures posted for the blood cell morphology proficiency tests. (A) HHI-1701 basophil (arrow). (B) HHI-1702 rouleaux formation (arrows). (C) HHI-17-03 blast (arrows). (D) HHI17-04 fragmented cell (schistocyte) (arrows). 


\section{Journal of LABORATORY MEDICINE and QUALITY ASSURANCE}

Young Kyung Lee et al • Annual Report on EQA for Routine Hematology

Table 4. Proficiency test results for blood cell morphology

\begin{tabular}{|c|c|c|c|}
\hline Trial & Code & Morphology & No. (\%) \\
\hline \multirow[t]{13}{*}{ HHI-17-01 } & Total & & $628(100.0)$ \\
\hline & 110 & Basophil & $599(95.4)$ \\
\hline & 462 & Basophilic stippling & $12(1.9)$ \\
\hline & 109 & Immature basophil & $4(0.6)$ \\
\hline & 119 & Toxic granulation & $3(0.5)$ \\
\hline & 103 & Myelocyte & $2(0.3)$ \\
\hline & 108 & Eosinophil & $2(0.3)$ \\
\hline & 106 & Segmented neutrophil & $1(0.2)$ \\
\hline & 468 & Rouleaux formation & $1(0.2)$ \\
\hline & 115 & Myeloblast with Auer rod & $1(0.2)$ \\
\hline & 104 & Metamyelocyte & $1(0.2)$ \\
\hline & 328 & Large granular lymphocyte & $1(0.2)$ \\
\hline & 105 & Band neutrophil & $1(0.2)$ \\
\hline \multirow[t]{7}{*}{ HHI-16-02 } & Total & & $628(100.0)$ \\
\hline & 468 & Rouleaux formation & $611(97.3)$ \\
\hline & 469 & Red cell agglutinates & $11(1.8)$ \\
\hline & 110 & Basophil & $2(0.3)$ \\
\hline & 434 & Normal red cell & $2(0.3)$ \\
\hline & 462 & Basophilic stippling & $1(0.2)$ \\
\hline & 454 & Spherocyte & $1(0.2)$ \\
\hline \multirow[t]{13}{*}{ HHI-17-03 } & Total & & $621(100.0)$ \\
\hline & 693 & Blast & $423(68.1)$ \\
\hline & 329 & Reactive lymphocyte & $92(14.8)$ \\
\hline & 327 & Lymphocyte & $45(7.2)$ \\
\hline & 330 & Lymphoma cell & $21(3.4)$ \\
\hline & 224 & Monocyte & $14(2.3)$ \\
\hline & 328 & Large granular lymphocyte & $7(1.1)$ \\
\hline & 103 & Myelocyte & $6(1.0)$ \\
\hline & 115 & Myeloblast with Auer rod & $4(0.6)$ \\
\hline & 104 & Metamyelocyte & $3(0.5)$ \\
\hline & 102 & Promyelocyte & $3(0.5)$ \\
\hline & 223 & Immature monocyte & $2(0.3)$ \\
\hline & 453 & Fragmented cell (schistocyte) & $1(0.2)$ \\
\hline \multirow[t]{11}{*}{ HHI-17-04 } & Total & & $621(100.0)$ \\
\hline & 453 & Fragmented cell (schistocyte) & $564(90.8)$ \\
\hline & 456 & Sickle cell & $29(4.7)$ \\
\hline & 457 & Acanthocyte (spur cell) & $17(2.7)$ \\
\hline & 473 & Bite cell & $4(0.6)$ \\
\hline & 454 & Spherocyte & $2(0.3)$ \\
\hline & 693 & Blast & $1(0.2)$ \\
\hline & 458 & Burr cell & $1(0.2)$ \\
\hline & 689 & Hairy cell & $1(0.2)$ \\
\hline & 576 & Normal platelet & $1(0.2)$ \\
\hline & 450 & Target cell & $1(0.2)$ \\
\hline
\end{tabular}




\section{Journal of LABORATORY MEDICINE and QUALITY ASSURANCE}

Young Kyung Lee et al • Annual Report on EQA for Routine Hematology

차 HHI-17-04 (Fig. 1D)는 fragmented cell (schistocyte)에 $90.8 \%$ 일치율을 보였다(Table 4).

\section{고찰}

2016년 차세대 신빙도조사사업 시행에 따라 일반혈액검사 프로그램도 그 이전과는 상당히 큰 변화가 있었다[1,4]. 2015 년에는 총 4 차에 걸쳐 매 회차마다 $\mathrm{CBC}$ 는 정도관리물질 1 개,
세포형태는 사진 2개씩 시행되었으나[4], 2016년부터는 2차 에 걸쳐 매 회차마다 $\mathrm{CBC}$ 는 정도관리물질 3 개, 세포형태는 사진 2개씩 시행하였으며[1], 2017년은 차세대 신빙도조사사 업 체계로 시행된 두 번째 해였다. 2017년 일반혈액검사 프로 그램에는 1,2 회차 평균 1,490 기관이 참여하여 2016년의 평균 1,455 기관에 비해 35 기관이 늘어나 $2.4 \%$ 의 증가를 보였다[1].

결과 회신율은 $\mathrm{CBC}$ 는 $96.7 \%$ 로 2016년의 $96.3 \%$ 와 비교 하여 비슷한 수준을 보였으며, 세포형태검사의 결과 회신율은
2017년 1차 일반혈액검사 공통 보고서

\section{WBC count}

HH-17-01 WBC count

\begin{tabular}{|c|c|c|c|c|c|c|c|}
\hline All & $\begin{array}{r}N \\
1446\end{array}$ & $\begin{array}{c}\text { Mean } \\
16.305\end{array}$ & $\begin{array}{r}\text { SD } \\
0.631\end{array}$ & $\begin{array}{r}\mathrm{CV}(\%) \\
3.9\end{array}$ & $\begin{array}{r}\text { Median } \\
16.32\end{array}$ & $\begin{array}{l}\text { Min } \\
0.44\end{array}$ & $\begin{array}{c}\text { Max } \\
19.40\end{array}$ \\
\hline 1. Sysmex & 610 & 16.155 & 0.730 & 45 & 1630 & 000 & 1702 \\
\hline $\begin{array}{l}\text { 1. Sysmex } \\
\text { XN series }\end{array}$ & 163 & 1648 & 0270 & 1.6 & $\begin{array}{l}10.30 \\
16.49\end{array}$ & 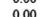 & 171 \\
\hline $\mathrm{XE}-2100$ & 99 & $\begin{array}{l}15.403 \\
15317\end{array}$ & 0.362 & 24 & 15.41 & 0.47 & 17.12 \\
\hline $\mathrm{XT}-1800 \mathrm{i}$ & 75 & 16.841 & 0.512 & 3.0 & $\begin{array}{l}16.41 \\
16.81\end{array}$ & 0.12 & 17.92 \\
\hline XP-300 & 72 & 16.220 & 0.522 & 3.2 & 16.20 & 14.02 & 17.20 \\
\hline $\mathrm{KX}-21 \mathrm{~N}$ & 64 & 16.107 & 0.437 & 2.7 & 16.10 & 14.05 & 17.00 \\
\hline $\mathrm{XE}-2100 \mathrm{D}$ & 46 & 15.403 & 0.321 & 2.1 & 15.44 & 14.64 & 17.19 \\
\hline $\begin{array}{l}\mathrm{XN}-550 \\
\mathrm{XS}-1000\end{array}$ & 27 & 16.748 & 0.355 & 2.1 & 16.71 & 9.29 & 17.66 \\
\hline $\begin{array}{l}\text { XS-1000i } \\
\text { XE-5000 }\end{array}$ & ${ }^{22}$ & $\begin{array}{l}16.733 \\
15.330\end{array}$ & 0.400 & 2.4 & 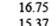 & $\begin{array}{l}15.33 \\
14.43\end{array}$ & 17.67 \\
\hline $\begin{array}{l}\mathrm{XE}-5000 \\
\mathrm{KX}-21\end{array}$ & ${ }_{11}^{12}$ & $\begin{array}{l}15.339 \\
16100\end{array}-3$ & 0.414 & 2.7 & $\begin{array}{l}15.37 \\
1610\end{array}-2$ & $\begin{array}{l}14.43 \\
13.50\end{array}$ & $\begin{array}{l}16.68 \\
1650\end{array}$ \\
\hline $\begin{array}{l}K X-21 \\
K-4500\end{array}$ & 11 & 16210 & . 0.372 & 2.12 & $\begin{array}{l}16.10 \\
1600\end{array}$ & $\begin{array}{l}13.50 \\
15.50\end{array}$ & 16.50 \\
\hline $\begin{array}{l}\mathrm{K}-4500 \mathrm{i} \\
\mathrm{XT}-2000 \mathrm{i}\end{array}$ & 9 & & & & $\begin{array}{l}10.84 \\
10.04\end{array}$ & $\begin{array}{l}15.51 \\
16.51\end{array}$ & $\begin{array}{l}17.03 \\
17.40\end{array}$ \\
\hline XS-800i & 3 & & & & $\begin{array}{l}10.84 \\
16.81\end{array}$ & $\begin{array}{l}10.51 \\
9.50\end{array}$ & $\begin{array}{l}17.40 \\
16.94\end{array}$ \\
\hline $\mathrm{XN}-350$ & 3 & & & & 16.71 & 16.63 & 16.91 \\
\hline pocH-100i & 2 & & & & & 15.10 & 16.20 \\
\hline 2. Nihon Kohden Corp. & 146 & 16.216 & 0.354 & 2.2 & 16.20 & 8.20 & 17.40 \\
\hline MEK- $6400 \mathrm{~K}, 6410 \mathrm{~K}, 6420 \mathrm{~K}$ & 64 & 16.226 & 0.312 & 1.9 & 16.20 & 9.10 & 16.90 \\
\hline MEK- $82222 \mathrm{~K}$ & 42 & 16.033 & 0.287 & 1.8 & 16.00 & 8.20 & 17.21 \\
\hline MEK-6500K $6510 \mathrm{~K}$ & 30 & 16.511 & 0.377 & 2.3 & 16.50 & 9.40 & 17.40 \\
\hline MEK-6318K & 6 & & & & 16.08 & 15.70 & 16.84 \\
\hline MEK- $7222 \mathrm{~K}$ & 3 & & & & 16.20 & 15.60 & 16.80 \\
\hline 3. Shenzhen Mindray Bio-Medical Electronics Co., Ltd. & 132 & 16.456 & 0.582 & 3.5 & 16.40 & 6.00 & 18.20 \\
\hline BC-5800 & 33 & 16.508 & 0.520 & 3.2 & 16.49 & 6.00 & 17.50 \\
\hline BC-3000Plus & 30 & 16.478 & 0.427 & 2.6 & 16.30 & 15.90 & 17.30 \\
\hline BC-2800 & 17 & 17.118 & 0.671 & 3.9 & 17.00 & 14.30 & 18.20 \\
\hline BC-6800 & 16 & 15.864 & 0.317 & 2.0 & 15.77 & 15.45 & 16.49 \\
\hline $\begin{array}{l}\text { BC- }-3600 \\
\text { BC- } 5380\end{array}$ & 15 & 16.239 & 0.534 & 3.3 & 16.40 & 15.20 & 17.20 \\
\hline & & & & & & & \\
\hline (9A) 대한임상검사정도관리형의 & & & & & & & $3 / 44$ \\
\hline
\end{tabular}

2017년 1차 일반혈액검사 기관별 보고서

기관번호: 기관명:

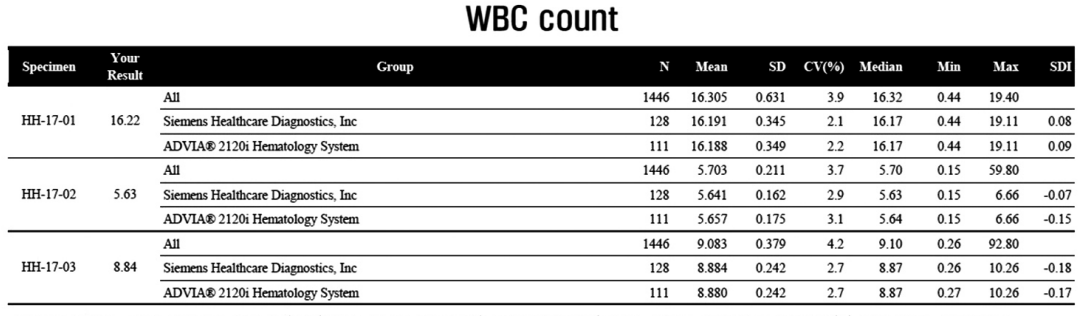

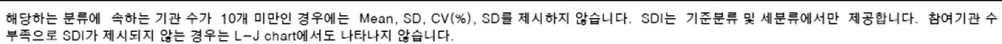
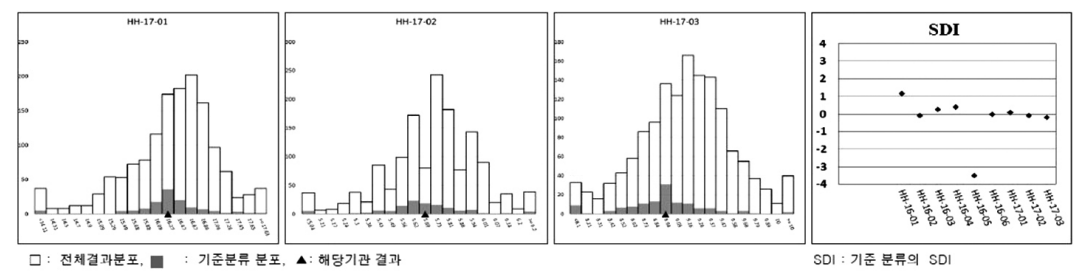

대산입상겅사정도관리영의
$2 / 8$ (B)
Fig. 2. Summary report of the Routine Hematology Program. (A) Summary of all participants. (B) Summary of each laboratory. 


\section{Journal of LABORATORY MEDICINE and QUALITY ASSURANCE}

Young Kyung Lee et al • Annual Report on EQA for Routine Hematology

42.0\%로 2016년의 40.4\%에 비해 증가하였다. 세포형태검사 의 결과 회신율이 낮은 값을 보이는 것은 2016년 차세대 신빙 도조사사업부터 $\mathrm{CBC}$ 와 세포형태를 구분하지 않고 일반혈액 프로그램을 신청하면 두 검사항목 모두 신청되도록 하였기 때 문으로, 회신한 기관의 수를 비교하면 차세대 신빙도조사사업 이전인 2015년에 503기관으로, 이후인 2016년에는 588기관, 2017년에는 625기관으로 점차 증가하고 있는 양상이다[1,4].

2016년 차세대 신빙도조사사업 이후 변화된 체계에 따라 2017년에도 모든 프로그램에 대해 정도관리물질의 발송부터 결과입력, 보고서 발송까지 전 과정을 협회 중앙에서 일관되게 관리, 진행하였다. 검체 발송은 다른 프로그램의 정도관리물질 과 함께 예약된 택배로 진행되었다. 1회차에서는 2017년 7월 3일, 2회차에서는 2017년 8월 29일에 $\mathrm{CBC}$ 정도관리물질이 발송되었는데, 기온이 높은 여름철에 배송함으로 인해 원거리 이거나 배송이 어려운 지역에서 검체 용혈이 발생되는 경우가 있어 향후 좀 더 기온이 낮은 시기에 배송함으로써 검체의 안 정성을 높일 수 있을 것으로 생각한다.

검체 수령 시 각 기관에서는 협회 차세대 신빙도조사사업 홈 페이지에서 검체 접수를 한 후, 검사를 시행하고 결과를 홈페 이지에 직접 입력한 후, 최종전송을 해야 결과가 전송되도록 하였다. 입력기간 종료 후 입력결과에 대하여 오류를 점검하 고, 통계분석을 시행하였으며, 결과통보 역시 차세대 신빙도조 사사업 홈페이지에서 참여기관별로 직접 조회 및 출력을 할 수 있도록 하였다. 결과보고서는 공통보고서와 기관별보고서 두 가지 형태로 제공하였으며, 공통보고서에는 전체기관, 그리고, 제조사별, 기기별 통계를 제공하였다. 기관별 보고서에서는 각 기관의 결과값과 전체, 그리고 기관에서 사용하는 기기의 제조 사, 기기분류에 따른 통계값과 $\mathrm{SDI}$ 를 제공하였으며, 전체기관 및 동일 제조사를 사용하는 기관들에서 해당 기관의 결과값의 위치를 히스토그램으로 제공하고, 해당 기관의 SDI의 누적분 포를 그래프로 표시하여 제공하였다(Fig. 2).

통계분석 시 소수점 표시 착오 등 입력오류로 판단되는 것은 수기로 제외하고, 이상치에 해당하는 결과값은 Turkey의 boxplot방식을 이용한 사분위법 의 이상치 제거를 적용하여 통계 분석에서 제외하였다[3]. 통계범위에 들어오는 기관만을 대 상으로 평균과 $\mathrm{SD}, \mathrm{CV}$ 를 계산하였으며, 각 기관의 평가결과 는 $\mathrm{SDI}$ 로 제시하였다. 이에 따라 일반혈액검사의 통계분석 제 외기관은 1 차에서는 $2.1 \%-7.1 \%, 2$ 차에서는 $2.4 \%-5.6 \%$ 였다
(Table 3).

$\mathrm{CBC}$ 에 사용된 기기의 현황은 Sysmex가 $42.9 \%$ 로 가장 많 았고, 다음으로 Nihon Kohden Corp., Siemens Healthcare Diagnostics Inc., Shenzhen Mindray Bio-Medical Electronics Co. Ltd., Horiba Medical, Beckman Coulter Inc. 등이 분포하여 주요 사용기기의 분포는 2016년과 유사하 였다[1].

수행능 측면에서 $\mathrm{CBC}$ 의 백혈구 수, 적혈구 수, 혈색소, 적혈구용적률, 혈소판 수의 $\mathrm{CV}$ 는 각각 $3.7 \%-4.7 \%, 2.2 \%-$ $2.4 \%, 1.5 \%-3.0 \%, 5.4 \%-6.0 \%, 7.2 \%-10.2 \%$ 범위로, 2016 년의 각 검사항목의 $\mathrm{CV} 3.8 \%-4.5 \%, 1.9 \%-2.3 \%, 1.4 \%-$ $2.8 \%, 4.8 \%-5.8 \%, 6.2 \%-9.4 \%$ 와 비슷한 분포였다[1]. 세포 형태는 2회차의 HHI-17-03의 경우 blast에 대해 $68.1 \%$ 로 다 소 낮은 일치율을 보였으나, 그 외 모든 회차에서 참여기관 간 에 $80 \%$ 이상의 일치율을 보였다.

2017년 일반혈액검사 프로그램은 2016년 차세대 신빙도조 사사업이 시행됨에 따라 전 과정이 전체 프로그램과 함께 협회 중앙에서 일괄 시행되었으며, 참여기관은 전년에 비해 다소 증 가를 보였고, 수행능 측면에서는 비슷한 결과를 보였다.

\section{REFERENCES}

1. Lee YK; Routine Hematology Program, Korean Association of External Quality Assessment Service. Annual report on the external quality assessment scheme for routine hematology in Korea (2016). J Lab Med Qual Assur 2017;39:53-60.

2. Klee GG, Westgard JO. Quality management. In: Burtis CA, Ashwood ER, Bruns DE, editors. Teitz textbook of clinical chemistry and molecular diagnostics. 5th ed. St. Louis (MO): Elsevier Saunders, 2012:163-203.

3. Turkey JW. Exploratory data analysis. Reading (MA): Addison-Wesley, 1977.

4. Kwon GC, Kim J, Ra GS; Diagnostic Hematology Subcommittee; Korean Association of External Quality Assessment Service. Annual report on the external quality assessment for diagnostic hematology in Korea (2015). J Lab Med Qual Assur 2016;38:1-10. 
일반혈액검사 신빙도조사 결과보고(2017) 이영경, - 김영민 $^{2}$

${ }^{1}$ 한림대학교 의과대학 진단검사의학교실, ${ }^{2}$ 한림대학교성심병원 진단검사의학과

대한임상검사정도관리협회 일반혈액검사 프로그램에서는 2017년에 전혈구계산(complete blood count, $\mathrm{CBC}$ )과 세포형태에 대한 신빙도조사를 시행하였다. 총 2회 시행하였으며, $\mathrm{CBC}$ 는 매 회차 3 개 농도의 정도관리물질을 배송하였고, 세포형태는 매 회차 2장의 사진을 웹사이트에 게시하였다. 일반혈액검사는 총 1,646기관이 참여하였고 $\mathrm{CBC}$ 는 회신율이 $96.7 \%$ 였으며, 세포형태검사는 회신 율이 $42.0 \%$ 였다. 신빙도조사사업에 사용된 장비의 현황은 전년도와 비슷하였다. 백혈구 수, 적혈 구 수, 혈색소, 적혈구용적률, 혈소판 수의 CV는 각각 3.7\%-4.7\%, 2.2\%-2.4\%, 1.5\%-3.0\%, 5.4\%-

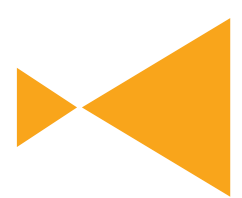

Journal of LABORATORY MEDICINE and

QUALITY ASSURANCE $6.0 \%, 7.2 \%-10.2 \%$ 범위였다. 세포형태는 $H H-17-03$ 을 제외하고 모든 회차에서 참여기관 간에 $80 \%$ 이상의 일치율을 보였다. 전년도에 비해 2017년도 외부정도관리사업 참여기관의 수는 증가하 였으며, 일반혈액검사의 수행능은 유사하였다.

(J Lab Med Qual Assur 2018;40:1-8) 